\title{
Value of Testing Loads in Determining the Functional State of the Athletes Body
}

\author{
Vanyushin Y.S. \\ Department of Physical Education \\ Kazan State Agrarian University \\ Kazan, Russia \\ kaf.fv.kgau@mail.ru
}

Elistratov D.E.

Department of Physical Education

Kazan State Agrarian University

Kazan, Russia

kaf.fv.kgau@mail.ru

\author{
Khairullin R.R. \\ Department of Physical Education \\ Kazan State Agrarian University \\ Kazan, Russia \\ kaf.fv.kgau@mail.ru
}

\begin{abstract}
The Use of testing loads to determine the functional state and identify the functional capabilities of athletes body is necessary in order to improve the quality of the training process and achieve high sports results. For this purpose it is necessary to choose appropriate testing loadings which will have scientific and practical value, both at survey of athletes, and for modification and additions in training occupations. When determining the functional state of the athlete's body, it is advisable to focus on testing loads of a dynamic nature. In this case, the individual characteristics of athletes associated with adaptive relationships between the components of the cardiorespiratory system are revealed. They are manifested in a variety of response options, depending on age characteristics, sports and physical activity capacity.
\end{abstract}

Keywords-testing physical activity; work capacity; Bicycle Ergometer; functional state.

\section{INTRODUCTION}

P. K. Anokhin (1980) proposed to consider human activity from the standpoint of physiology and psychology within a single functional architecture, focusing on the functional system as a "closed physiological formation with continuous feedback on the success of such adaptive action" (1). In his opinion, the functional state is a complex systemic reaction, dynamically changing in the process of activity and resulting from the interaction of functional systems of the human body. Therefore, the functional state must be considered as a result of the organism dynamic interaction with the external environment, reflecting the state of the "organized whole". Currently, the functional state is a functional background or factor that largely determines human behavior, its capabilities (including labor and related to exercise) and reflecting the features of regulatory processes in the norm and pathology (6). In this case, the background activity in which the activity is carried out is considered.

\section{LITERATURE REVIEW}

Application of various testing loadings modeling different sides of the environment is one of the principles laid down at the beginning of the last century by I. p. Pavlov (1999) (5). With their help, information can be obtained on the objective characteristics of the organism functional state (4). Such a test can be a change of the body position in space. This is a natural, not associated with the use of any additional effort functional test and is a model of everyday human loads, as well as the result of vegetative regulation. In this regard, to obtain a reliable assessment of the cardiovascular system adaptive capabilities, as part of the cardiorespiratory system, various tests with changes in body position are used. In addition, in medical and biological studies, motor actions with high diagnostic value have become widespread (8), (11). In this case, veloergometry is generally accepted and preferred, due to which it is possible to obtain physiological information during the work itself (3). The aim of the study was to identify testing loads of different physiological orientation and power to determine the of the athletes organism functional state.

\section{RESEARCH METHODOLOGY}

With an active change of body position, a group of male athletes aged 22-26 years, in the number of 20 people, was examined. They had an average body length of $175.45 \mathrm{~cm}$ and weight-73.90 kg. All subjects had orthostatic stability and they had the first minute of lying, sitting and standing by tetrapolar thoracic rheography by W. G. Kubicek et al. (1966), recorded differential rheogram and electrocardiogram to determine the shock and minute blood volume, as well as heart rate (10). 
When working on the Bicycle Ergometer gradually increasing power to 200 watts, male athletes aged 18 to 53 years, 108 people engaged in various sports and having sports qualifications from master of sports to 2 categories took part. In addition, a group of male athletes of (12 people) aged 19-44 years, with high total body size was examined.

In biomedical research, the following testing loads were used. Natural, not associated with the use of any additional effort, an active change in the position of the body in space (active orthostasis). It is the result of autonomic regulation and work on the bike Ergometer gradually increasing power with an accurate dosage of physical activity, through which it is possible to obtain physiological information during the motor activity. All these testing loads are widely used in the examination of athletes in the study of adaptation physiological mechanisms and in order to make changes in the training process for athletes to achieve high sports results in their chosen sport (2), (3)

\section{RESULTS}

The simplest and most accessible testing load is an active change in body position or an active orthostatic test used to detect shifts in the cardiovascular system and to monitor the recovery processes in the athlete's body. To clarify the shifts in the initial period of active changes in body position, we used an orthostatic test, as a result of which it was found that during the transition from a lying position to a standing position, called partial orthostasis, within the first minute after changing the position of the body, the IOC changes by a significant value (table. 1). In the first ten seconds it was associated with changes in heart rate, and at the end of the first minute-with shifts only in heart rate. In this regard, we distinguish two phases of cardiac output compensatory reactions. The first-the duration from the beginning of the study to ten seconds is characterized by pronounced tachycardia and a decrease in UOC. The second phase $(50-60 \mathrm{~s})$ is manifested in the stabilization of shock emission and decrease in heart rate. All this is reflected in the undulating nature of the IOC changes.

TABLE I. INDICATORS OF HEART ACTIVITY IN THE GROUP OF ATHLETES IN THE INITIAL PERIOD OF ACTIVE CHANGE OF BODY POSITION

\begin{tabular}{|l|l|l|c|c|c|}
\hline \multirow{2}{*}{ Indicators } & \multicolumn{5}{|c|}{ Position of the subject } \\
\cline { 2 - 6 } & \multirow{2}{*}{$\begin{array}{c}\text { Lying } \\
\text { down }\end{array}$} & \multicolumn{2}{|c|}{ Sit } & \multicolumn{2}{c|}{ Standing } \\
\cline { 3 - 6 } & $0-10 \mathrm{c}$ & $50-60 \mathrm{c}$ & $0-10 \mathrm{c}$ & $50-60 \mathrm{c}$ \\
\hline SVB, ml & $109.84^{*}$ & $93.93^{*}$ & 91.77 & $91.43^{\mathrm{O}}$ & $77.37^{\mathrm{O}}$ \\
& 3.34 & 3.65 & 3.88 & 3.17 & 3.04 \\
\hline $\begin{array}{l}\text { Heart } \\
\text { rate, } \\
\text { beats/min }\end{array}$ & $67.84^{*}$ & $86.97^{*+}$ & $74.74^{+\mathrm{X}}$ & $87.80^{\mathrm{X}}$ & 85.85 \\
\hline $\begin{array}{l}\text { MVB, } \\
\text { 1/min }\end{array}$ & 2.04 & 2.45 & 2.63 & 2.18 & 2.82 \\
\hline
\end{tabular}

body positions and time intervals.
During the transition to the standing position, changes in the magnitude of cardiac output are associated only with significant shifts in the SVB index, and the chronotropic response of the heart is not leading in maintaining the MOC. In this case, two phases of compensatory shifts can also be distinguished: the first $(0-10 \mathrm{~s})$ - marked by a significant increase in the chronotropic response of the heart and the invariance of the shock volume, and the second (50-60 s) by reverse phenomena. Therefore, in the first seconds of the body changing position there are primary effects, and in the future secondary, compensatory, aimed at eliminating the primary changes in blood circulation and thereby preserving circulatory homeostasis.

Work on veloergometre gradually-increasing power up to $200 \mathrm{~W}$ led to the fact that manifested one of the cardiorespiratory system reactions: inotropic, chronotropic, respiratory or mixed (chronotropic-respiratory, inotropicrespiratory) (tab. II). The most optimal of these reactions is the reaction associated with an increase in the inotropic function of the heart, since it can contribute to improving physical performance and sports results by increasing the functional reserve of the circulatory and respiratory systems. Load capacity of $3 \mathrm{~W} / \mathrm{kg}$, which we attributed to the loads of maximum power, contributed to the identification of a mixed type of reaction: chronotropic-respiratory; inotropicrespiratory (table. III). (3), which indicates additional mechanisms to provide the body with oxygen during motor activity, requiring significant energy costs.

TABLE II. TYPES OF REACTION OF CARDIORESPIRATORY SYSTEM IN GROUPS OF ATHLETES AT VELOERGOMETRIC LOADING WITH POWER IN $200 \mathrm{~W}$.

\begin{tabular}{|l|c|c|l|}
\hline \multirow{2}{*}{ Reaction type } & \multicolumn{3}{|c|}{ Performance } \\
\cline { 2 - 4 } & $\begin{array}{c}\text { Heart rate, } \\
\text { beats/min }\end{array}$ & WALK, ml & \multicolumn{1}{|c|}{ MOD, 1} \\
\hline Inotropic & 141.83 & 147.53 & 58.51 \\
& \pm 1.55 & \pm 2.18, \\
& KV=9.21\% & \pm 1.16 \\
\hline Chronotropic & 169.34 & 103.96 & 63.04 \\
& \pm 0.83, & \pm 2.59 & \pm 0.76 \\
& $\mathrm{KV}=3.01 \%$ & & \\
\hline Respiratory & 149.42 & 112.11 & 78.71 \\
& \pm 2.49 & \pm 4.96 & \pm 2.70, \\
& & & $\mathrm{KV}=9.72 \%$ \\
\hline Chronotropic- & 173.62 & 111.88 & 84.35 \\
respiratory Heart & \pm 2.99 & \pm 5.29 & \pm 2.44, \\
rate MOD-MVB & & & $\mathrm{KV}=8.66 \%$ \\
\hline Inotropic SVB- & 146.74 & 144.75 & 86.83 \\
MVB & \pm 1.87 & \pm 3.64, & \pm 2.07, \\
& & $\mathrm{KV}=8.70 \%$ & $\mathrm{KV}=8.24 \%$ \\
\hline
\end{tabular}

The study showed that the active change in body position, which we refer to minimal physical exertion, a set of cardiorespiratory system indicators takes part in the compensatory-adaptive reactions of athletes and among them it is impossible to allocate a leading factor in the adaptation of the organism. Therefore, the value of the proposed physical activity is leveled by the results of the research, indicating the low importance of this load.

Use of the last two loadings for identification of features in activity of athletes organism acquires important 


\section{References}

scientific and practical value, as the additional factor of athletes functional condition control and modification of a mode of training occupations.

TABLE III. TYPES OF REACTION OF CARDIORESPIRATORY

SYSTEM IN GROUPS OF ATHLETES AT VELOERGOMETRIC LOADING WITH A POWER OF $3 \mathrm{~W} / \mathrm{KG}$

\begin{tabular}{|l|l|c|c|}
\hline \multirow{2}{*}{ Type of reaction } & \multicolumn{3}{|c|}{ Performance } \\
\cline { 2 - 4 } & $\begin{array}{c}\text { Heart rate, } \\
\text { beats/min }\end{array}$ & WALK, ml & MOD, 1 \\
\hline Inotropic & 146.34 & 135.29 & 60.37 \\
\pm 4.15 & 119.53 & \pm 2.06 \\
\hline Respiratory & 157.89 & \pm 3.27 & 85.63 \\
& \pm 5.61 & 107.67 & 84.60 \\
\hline Chronotropic- & 171.46 & \pm 9.03 & \pm 3.88 \\
respiratory Heart rate- & \pm 2.10 & & KV \\
MVB & $\mathrm{KV}=2.75 \%$ & 149.70 & $9.95 \%$ \\
& & \pm 5.02 & \pm 2.48 \\
\hline Chronotropic - & 184.09 & KV $=7.51$ & KV $=$ \\
Inotropic respiratory & \pm 1.39 & $\%$ & $5.81 \%$ \\
Heart rate & $\mathrm{KV}=1.69 \%$ & \\
SVB & \multicolumn{3}{|c}{} \\
MVB & \multicolumn{3}{|c}{} \\
\hline
\end{tabular}

\section{CONCLUSIONS}

When determining the functional state of the athlete's body, it is advisable to focus on testing loads of a dynamic nature. In this case, their individual characteristics associated with adaptive relationships between the components of the cardiorespiratory system are revealed, manifested in a variety of response options that depend on age characteristics, sports and the power of physical activity used. Therefore, the identification of testing loads value for their subsequent use will contribute to the correct construction of the training process.
[1] Anokhin P. K. Nodal issues of functional system theory. Moscow: Nauka. 1980, 197

[2] Sudakov K. V. Physiology. Fundamentals and functional systems: a course of lectures. M., Medicine. 2000, 784.

[3] Pavlov I.P. Selected works. Moscow: Meditsina. 1999, 445.

[4] Elistratov D. E. Functional state of the cardiovascular system under physical activity / / Actual problems of physical culture and sport in modern socio-economic conditions: Materials of the International scientific and practical conference. Cheboksary: Chuvash state agricultural Academy doctor. 2016, pp. 209-212.

[5] Ashley E. A., Kardos A., Ashley E. A., Jack E. S. Angiotensisconverting enzyme genotype predicts cardiac and autonomic responses to prolonged exercise. J. Am. Coll. Cardiol. 2006, vol. 48, 3, pp. 523531.

[6] Hopkins S. R. The lung maximal exercise: insights from comparative physiology. Clin. Chest. Med. 2005, vol. 26, 3, pp. 459-468.

[7] Vanyushin Yu. S., Khairullin R. R. Cardiorespiratory system in ontogenesis during adaptation to functional loads. Kazan: Fatherland. 2016, 200.

[8] Fedorov N. A., Elistratov D. E., Vanyushin Yu. S. Comprehensive assessment of the functional state of students. Kazan: kgau. 2014, 86.

[9] Kubicek W. G., Karnegis I. N., Patterson R. P. et. al. Development and evolution of an impedance cardic output system. Aerosp. Med.1966, vol. 37, 12, pp. 1208-1212.

[10] Vanyushin Yu. S., Khairullin R. R. Cardiorespiratory system as an indicator of the functional state of the organism of athletes. Theory and practice of physical culture. 2015, 7, pp. 11-14.

[11] Streltsov, L. I., Tkacheva O. N., Dudinskaya E. N., Akasheva D. W., E. V. Plokhova, D. Strazhesko I., Boytsov S. A. Age-related changes in heart rate variability with different insulin sensitivity and telomere length. Cardiology. 2017, vol. 57, 7, pp. 52-60.

[12] Yurij S.Vanyushin, Nikolay A. Fedorov, Guliya K. Khuzina, Ahmet G. Yarullin. Criteria of biological security of a growing organism and mature athletes. Russian Journal of Physical Education and Sport. 2019, 14(2): 82-86. DOI: 10.14526/2070-4798-2019-14-2-97-102. 